\title{
Care of the injured worldwide: trauma still the neglected disease of modern society
}

\author{
Joseph V Sakran ${ }^{1,2^{*}}$, Sarah E Greer ${ }^{2}$, Evan Werlin ${ }^{3}$ and Maureen McCunn ${ }^{4}$
}

\begin{abstract}
Traditionally, surgical diseases including emergency and injury care have garnered less attention and support internationally when compared to other medical specialties. Over the past decade however, healthcare professionals have increasingly advocated for the need to address the global burden of non-communicable diseases. Surgical disease, including traumatic injury, is among the top causes of death and disability worldwide and the subsequent economic burden is substantial, falling disproportionately on low- and middle-income countries (LMICS). The future of global health in these regions depends on a redirection of attention to diseases managed within surgical, anesthesia and emergency specialties. Increasing awareness of these disparities, as well as increasing focus in the realms of policy and advocacy, is crucial. While the barriers to providing quality trauma and emergency care worldwide are not insurmountable, we must work together across disciplines and across boundaries in order to negotiate change and reduce the global burden of surgical disease.
\end{abstract}

\section{Global burden of trauma and emergency surgical disease}

Global support for surgical diseases including emergency and injury care has garnered less attention when compared to other medical specialties. Over the past decade however, healthcare professionals have increasingly advocated for the need to address the global burden of non-communicable diseases, which includes surgical care and its related specialties. The future of global health in low- and middle-income countries (LMICs) depends on a redirection of attention to diseases managed within surgical, anesthesia, emergency medicine and critical care specialties.

In 1966, the United States (U.S.) National Academy of Sciences published the influential report titled Accidental Death and Disability: The Neglected Disease of Modern Society, more commonly known as The White Paper. This landmark report was vital in the development of the emergency medical services system in the U. S. [1], leading to significant improvement in prehospital care, coordination of care within trauma systems, as

\footnotetext{
* Correspondence: sakran@musc.edu

'Department of Surgery, Medical University of South Carolina, 96 Jonathan Lucas Street (MSC 613/CSB 420), Charleston, SC 29425-6130, USA

${ }^{2}$ Department of Surgery, Hospital of the University of Pennsylvania, 3400

Spruce Street, Maloney 5, Philadelphia, PA 19104, USA

Full list of author information is available at the end of the article
}

well as a focus on functional rehabilitation. Trauma and emergency care systems have continued to mature over the past five decades in the U.S. and other highlydeveloped nations, in contrast to LMICs where such organization and infrastructure is virtually non-existent. This review specifically does not focus so much on short term interventions, and aims to discuss sustainable longterm interventions that will bolster the health infrastructure in LMICs.

\section{Disparities in access to surgical care}

Surgical disease, including traumatic injury, is among the top causes of death and disability worldwide [2]. Though much of the literature on the global burden of surgical disease is based on modeling and subjective surveys, it is clear that significant disparities exist and that access to care in LMICs varies widely. In 2004, it was estimated that only $3.5 \%$ of 234 million major surgical procedures were performed on the world's poorest 35\% (those with health care expenditures $<\$ 100$ per capita). In contrast, $74 \%$ of the surgeries were performed on the $30 \%$ of individuals from countries with health care expenditures $>\$ 1000$ per capita [3].

Using modeling data from 192 World Health Organization (WHO) states, it was estimated that in countries with health care expenditures $<\$ 100$ per capita, the rates of surgery were only 295 per 100,000 
[3]. These estimations were confirmed in a retrospective study of 8 district hospitals across Tanzania, Uganda and Mozambique (countries with health care expenditures of 22, 44, and 21 dollars respectively), where the median annual rate of major surgical procedures was 25 per 10,000 [4].

\section{Disability due to surgical disease}

The repercussions of poor access to surgical care are highlighted by the staggering impact of untreated surgical disease worldwide. Estimates suggest that 11\% of the world's disability adjusted life years, or DALYs (an estimation of years of healthy life lost due to disease or disability), are due to conditions that could be adequately treated with surgery [5]. The worldwide DALYs lost due to surgical disease are 27 per 1,000, and this burden is felt disproportionally by LMICs. The African continent reports 38 DALYs per 1,000 in comparison to the Americas which report 21 DALYs per 1,000, well below the worldwide average [5]. Due to variable reporting and registry quality, the true estimation of years of healthy life lost due to disease is likely even greater.

These global statistics are reflected locally in a study at a 90-bed hospital in Sierra Leone. Inpatient surgical care comprised only $1.7 \%$ of the hospital's 8598 total contacts in a 3-month period. However, the appropriate delivery of surgical services averted the loss of $15 \%$ of the hospital's DALYs during the same period. Basic outpatient surgical services such as suturing, fracture reduction or casting accounted for a significant portion of the hospital's caseload [5].

\section{Injury and trauma}

Traumatic injury is the leading cause of death under the age of 45 in the U.S. and worldwide [6]. Approximately 5.8 million people die each year as a result of injuries. This accounts for $10 \%$ of the world's deaths, more than the number of fatalities from malaria, tuberculosis and HIV/AIDS combined. Furthermore, ninety percent of these injury deaths occur in LMICs [2]. Because trauma affects a relatively younger population, it accounts for more productive years of work lost than other illness, with an enormous economic and societal impact.

The global burden of injury is inversely proportional to income. Mortality increases concomitantly with the decreasing economic level of a country, from 35\% mortality rates for injured patients (with Injury Severity Scores (ISS) > 9) in the U.S., to $55 \%$ in Mexico, to $63 \%$ in Ghana [7]. Eliminating these inequalities has the potential to result in 2,000,000 lives per year saved [7]. Injuries account for 63 million DALYs worldwide, with the highest per capita burden in Africa at 15 DALYs per $1,000[5]$.

\section{Mechanism of injury}

The mechanism of injury leading to traumatic death (blunt, penetrating, drowning, burns) may vary by region, country and the relative state of war or peace locally. Road traffic crashes are the second highest cause of DALYs in 10-24 year olds, accounting for 5.4\% of all DALYs; violence and self-inflicted injuries account for $3.5 \%$ and $2.8 \%$ respectively $[8,9]$. In countries with higher economic growth, access to motorized vehicles (automobiles, two- and three-wheelers) may exceed traffic system development: quality of roads, traffic signals, crosswalks, resulting in a higher rate of motor vehicle crashes. (See Figure 1) A number of LMICs have legislation in place for injury prevention (i.e. seatbelt or helmet law). However, the problem lies in enforcement of these laws: without the ability of many LMICs to enforce these laws, the prevention interventions become ineffective [10-13]. In 2004, traffic crashes accounted for $10 \%$ of all deaths globally in people aged 10-24 years [14]. With many of these crashes occurring in remote locations, a delay in care often occurs. Other barriers to getting patients immediate medical care are the actual terrain itself, (with most ground infrastructure being dirt roads riddled

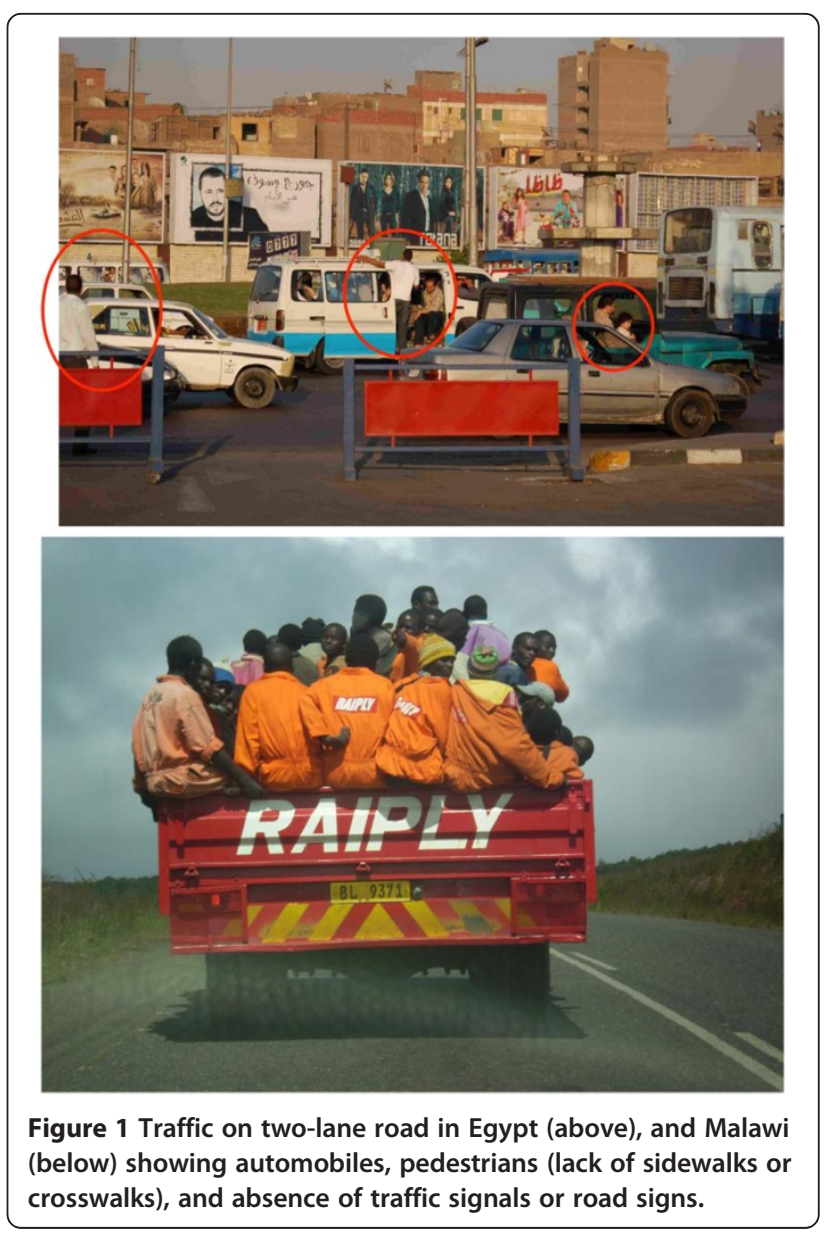


with pot-holes), lack of an organized pre-hospital transportation system, and inability to pay for transport to a hospital.

Violent injuries may be communal (war), interpersonal (assaults, firearms) or self-inflicted (poisoning, suicide). War and conflict leads not only to direct traumatic injury but also to injury more difficult to quantify, such as rape and torture [15], as well as the remnants of war, such as landmine injuries [16]. Patterns of injury seen in military conflicts [17-20] informs civilian care as new techniques for hemorrhage control and wound management are developed. Unfortunately these advances tend to occur primarily in higher-income countries where trauma system infrastructure already exists.

\section{Challenges to care}

A number of factors in LMICs contribute to the significant morbidity and mortality associated with injury and emergency, and is reflective of the problems with access to care. Potential barriers to providing surgical care to the world's poorest include a lack of effective political advocacy, insufficient resources (both personnel and consumables), and a perception that surgical intervention is not cost-effective by population-based measures.

\section{Prehospital care}

In the prehospital setting, availability of transportation and lack of organized emergency medical services are the most significant impediments to providing optimal care. Just as overall mortality rates increase with decreasing economic status, prehospital death rates are also inversely proportional to economic status [7]. In a study comparing prehospital death rates, 59\% of trauma deaths occurred in the field in high-income settings, compared to $72 \%$ in middle-income and $81 \%$ in lowincome environments [7].

The time it takes to reach definitive care impacts this increased mortality rate. In most countries, there is no centralized "911" emergency call system and the ill or injured must transport themselves or pay for a private ambulance. Across 48 medium to large sized hospitals in Kenya, only $52 \%$ of patients arrived at the hospital within 30 minutes after a road traffic injury, and only $72 \%$ within one hour [21].

Several countries have adapted non-Western models of pre-hospital care [22] with training of "first responders" in the lay public [23-25] as well as the training of taxi drivers as de facto prehospital personnel [26-28]. Longitudinal studies that report outcomes after system implementation may help inform future infrastructure development. With a variety of systems and potential solutions, it is important to recognize that no single practice is applicable in all settings, but rather that prehospital care for emergency services should be adapted to meet local community needs [23,29-31].

\section{Hospital factors}

The availability of international quality indicators is highly variable, and makes the objective assessment of care difficult. The WHO has played a prominent role in addressing this gap, and recognizes three categories pertaining to the provision of care where improvement efforts may be focused: physical resources (lack of equipment, or equipment that is not appropriately maintained), organizational resources (lack of performance improvement efforts), and human resources (lack of adequately trained staff). In 2004, the WHO working group publication Guidelines for Essential Trauma Care delineated 11 core essential services as well as 260 individual items (both physical and human resources) that should be available based on the level of care from small rural clinics to tertiary centers [32]. This publication, with its endorsement by the International Association of Trauma Surgery and Intensive Care (IATSIC), the International Trauma Anesthesia and Critical Care Society (ITACCS) and the International Society of Surgery, serves not only as a guideline for healthcare providers, but as an advocacy statement to prompt action [33,34].

\section{Physical resources}

The harsh reality of economics impacts in-hospital trauma and surgical care in a very direct fashion. Cash deposits are frequently demanded prior to treatment, and often require the signing of a binding agreement [21]. This practice is not uncommon in many LMICs where injured patients must provide proof of payment prior to receiving even emergency care. Patient and families are often required to procure their own medical supplies, including not only medications, but also bandages and surgical dressings [31].

Physical resources must be not only available but functional. Life-saving and disability-preventing surgical procedures can be achieved only in conjunction with appropriate anesthesia services. In a convenience sampling of 22 countries and a total of 590 facilities, 35\% of hospitals had no access to oxygen and $40 \%$ had no anesthesia machines Approximately $25 \%$ of facilities reported that they had no access to emergency airway equipment (laryngoscopes, endotracheal tubes, face masks) [35].

\section{Organizational resources}

Trauma surgery has a long history of incorporating performance improvement efforts into clinical practice, but many LMIC do not have this organizational infrastructure in place. The WHO provides guidelines for trauma care resources through the Global Initiative for 
Emergency and Essential Surgical Care [36] and Guidelines for Essential Trauma Care [32] which have been implemented in several countries. Implementation of basic performance improvement efforts to identify preventable deaths and address patient care issues has been shown to decrease mortality, such as when implemented at hospital in Khon Kaen, Thailand [37]. The importance of establishing and attaining benchmarks is a better understanding of the processes of patient care, and lies at the foundation of improving quality of care for all patients. Another effort to bridge the knowledge gap is on-line resources that provide free educational material tailored towards LMIC such as: http://www. primarytraumacare.org, http://www.trauma.org.

\section{Human resources}

There is a critical shortage of healthcare workers in LMICs. Disparities between global healthcare needs and the available workforce are due to multiple factors: lack of training, inadequate salary reimbursement, perceptions of a lack of professional status, and the "brain drain' to more highly developed countries. Sub-Saharan Africa carries $24 \%$ of the global burden of disease but as little as $3 \%$ of the world's health workers (http://www. who.int/surgery/globalinitiative/en/). Many trained and educated nationals who work in the healthcare field leave their home country for better pay, more opportunities or better education for their families, and in conflict zones, often to escape the risk of imprisonment or death for treating enemy forces.

This leaves local hospitals often unable to perform procedures at the desired level. In district hospitals within the war-ravaged zones of Sri Lanka, 35.7\% of the hospitals were unable to perform removal of a foreign body, $95 \%$ were unable to perform cricothyroidotomy or tracheostomy, and $60 \%$ were unable to perform chest tube insertion or burn management, opting instead to refer patients to other hospitals [38].

An issue that has been highlighted more recently is the fact that surgeons training in western societies continue to narrow their expertise as they become sub-specialized. One might see how this can spiral into a tremendous issue for LMICs that already deal with insufficient general surgery experts. This further supports training of non-physician providers that will be discussed in more detail below. In addition to the need for surgical expertise, the need for better anesthesia care and more anesthesiologists in LMICs is increasingly recognized as a healthcare concern. The World Health Assembly established a Task Force for Scaling Up Education and Training for Health Workers and identified several factors such as those listed above necessary for successful scale-up programs [39].
The high mortality rate associated with anesthesia in LMICs (as high as 1 death per 144 cases) is often ascribed to lack of training and oversight [40]. A recent survey to assess the availability of anesthesia providers in LMICs obtained information from Zambia, Yemen, Tanzania, Zimbabwe, Afghanistan, Senegal, Cameroon, Benin, the Democratic Republic of Congo, Rwanda, Uganda, and Cote d'Ivoir; Swaziland was the only country with more than one physician or non-physician anesthesia provider per 100,000 people [41-43]. A WHO survey tool administered to 344 health care facilities in LMICs showed $30 \%$ had no anesthesia provider in the medical facility, and $41 \%$ of anesthetics were delivered by uncertified, unlicensed and unregistered nonphysician providers [44].

\section{Interventions}

Of the 234 million surgical procedures performed worldwide, humanitarian aid organizations provide $50-100,000$ surgical interventions annually [45]. While the presence of foreign nationals may help to support a healthcare system for the short term, in the long term, capacity building and efforts to create sustainable programs to address unmet trauma, emergency, and anesthesia healthcare needs is mandatory. Several highly-developed nations have paired with LMICs to create training programs, establish universities, sustain hospital services, run trauma and emergency care courses, and organize exchange programs that allow practitioners to work abroad [46-49].

\section{Non-physician providers - 'task shifting'}

Several countries have utilized the concept of task shifting in order to use healthcare workers replace or supplement the work-shortage of physicians, particularly in rural areas. A recent review identified 31 studies from various countries that have instituted task shifting through the use of non-physician providers, suggesting this is a promising policy option to increase productivity in provision of health care services as well as standardize the services provided at a given quality and cost [50]. This has been successfully implemented for trauma surgery in Cambodia [51]. A focused discussion of surgery and anesthesia needs in Africa also identified the value of task shifting, where surgical procedures and anesthetics are performed by other providers when physicians are not available [52].

\section{Additional training}

The American College of Surgeons Advanced Trauma Life Support $\left(\mathrm{ATLS}^{\circledR}\right)$ course offers a basic foundation in the principles and practice of trauma care, but with significant impact. Institution of ATLS in Trinidad was associated with a decrease in mortality from $67 \%$ to $34 \%$ for severely injured patients $[53,54]$. Other efforts to 
provide additional training as well as further opportunity for exchange between surgeons across countries have demonstrated benefit $[55,56]$. Commonalities in knowledge, training, and previous experiences will allow for formation of interdependent multidisciplinary teams. Trauma team training, as occurs in the military and in high-income nations, can also be implemented in hospitals in LMICs [57].

Global anesthesia outreach in education and local training of anesthesia providers is a short-term strategy supported by the WHO to improve the quality and quantity of providers in countries with insufficiently met needs [41]. The sustained presence of Western-trained anesthesiologists, in rotation or for several months' time, could contribute to the training and education of providers in developing nations. Support for LMICs to develop their own education and training, to institute programs for the specialty of anesthesia, and to adopt the practice of 'task shifting', would help to lessen the gap between need and availability of qualified providers. An approach to addressing global health care needs is seen in the Medical School for International Health, a partnership between Ben-Gurion and Columbia universities. This unique program prepares students to work both in medicine and an international health setting, emphasizing the practice of preventive and population based medicine across cultures [58].

\section{Future directions}

The global burden of trauma and emergency surgical disease is vast and includes anesthesia services; pre-hospital systems; and physical, human and organizational resource availability. There is a growing recognition among health care providers however, that the future of global health in low- or middle-income countries (LMICs) depends not only on addressing communicable diseases, but focusing attention on diseases managed within surgical, anesthesia, and emergency care specialties. Increasing the awareness of existing disparities, as well as stakeholder involvement in the realms of policy and advocacy is vital to improving the current situation. The barriers to providing quality trauma and emergency care worldwide are not insurmountable - but we must work together across disciplines and across borders if we are to raise the bar and negotiate change. Our patients deserve no less.

\section{Competing interests}

The authors declare that they have no competing interests.

\section{Authors' contributions}

Design - JS, SG, EW, MM Literature Review - JS, SG, EW, MM Analysis of Data - JS, SG, EW, MM Writing of Manuscript - JS, SG, EW, MM All authors read and approved the final manuscript.

\section{Author details}

'Department of Surgery, Medical University of South Carolina, 96 Jonathan Lucas Street (MSC 613/CSB 420), Charleston, SC 29425-6130, USA.

${ }^{2}$ Department of Surgery, Hospital of the University of Pennsylvania, 3400 Spruce Street, Maloney 5, Philadelphia, PA 19104, USA. ${ }^{3}$ Perelman School of Medicine, University of Pennsylvania, 3400 Spruce Street, Maloney 5, Philadelphia, PA 19104, USA. ${ }^{4}$ Department of Anesthesiology and Critical Care, Hospital of the University of Pennsylvania, 3400 Spruce Street, Dulles 6, Philadelphia, PA 19104, USA.

Received: 26 June 2012 Accepted: 11 September 2012

Published: 15 September 2012

\section{References}

1. Accidental death and disability: the neglected disease of modern society. Washington D.C: National Research Council, National Academy of Sciences; 1966.

2. World Health Statistics. 2011 http:/www.who.int/whosis/whostat/2011/en/ indext.html.

3. Weiser TG, Regenbogen SE, Thompson KD, Haynes AB, Lipsitz SR, Berry WR: An estimation of the global volume of surgery: a modelling strategy based on available data. Lancet 2008, 372:139-144.

4. Galukande M, Schreeb JV, Wladis A, Mbembati N, Miranda HD, Kruk ME: Essential surgery at the district hospital: a retrospective descriptive analysis in three African countries. PLOS Medicine 2010, 7:1-10.

5. Debas HT, Gosselin R, McCord C, Thind A: Surgery. In: Disease Control Priorities in Developing Countries. 2nd edition. Oxford: Oxford University Press; 2006:1245-1259.

6. Institute of Medicine Committee on Injury Prevention and Control: Reducing the burden of injury: advancing prevention and treatment. Washington, DC: National Academy Press; 1999.

7. Mock CN, Jurkovich GJ, nii-Amon-Kotei D, Arreola-Risa C, Maier RV: Trauma mortality patterns in three nations at different economic levels: implications for global trauma system development. Journal of Trauma, Injury, Infection, and Critical Care 1998, 44:804-812.

8. Gore FM, Bloem PJ, Patton GC, Ferguson J, Joseph V, Cofey C: Global burden of disease in young people aged 10-24 years: a systematic analysis. Lancet 2011, 377:2093-2102.

9. The global burden of disease: 2004 update. http://www.who.int/entity/ healthinfo/global_burden_disease/GBD_report_2004update_full.pdf.

10. Jaung MS, Y Y S, Stallones $L$, Xiang $H$ : Road traffic injuries among middle school students in a rural area of China. Traffic Injury Prevention 2009, 10:243-251.

11. Bashir MO, Abu-Zidan FM: Motor vehicle collisions with large animals. Saudi Medical Journal 2006, 27:1116-1120.

12. Fallahzadeh $H$, Dehgani A: Epidemiology of road traffic mortality and injuries in Yazd, Iran during 2003-2008. Chinese Journal of Traumatology 2011, 14:293-296.

13. Bacchieri G, Barros AJ: Traffic accidents in Brazil from 1998 to 2010: many changes and few effects. Revista de Saude Publica 2011, 45:949-963.

14. Patton GC, Cofey C, Sawyer SM, Viner RM, Haller DM, Bose K: Global patterns of mortality in young people: a systematic analysis of population health data. Lancet 2009, 374:881-892.

15. Mukwege D: No more! Organized rape in the Democratic Republic of the Congo must stop now. International Journal of Gynecology \& Obstetrics 2011, 114:1-3.

16. Bilukha OO, Laurenge $\mathrm{H}$, Danee L, Subedi KP, Becknell K: Injuries and deaths due to victim-activated improvised explosive devices, landmines and other explosive remnants of war in Nepal. Injury Prevention 2011, 17:326-331.

17. Kummoona RK: Missile war injuries of the face. Journal of Craniofacial Surgery 2011, 22:2017-2021.

18. Pannell D, Brisebois R, Talbot M, Trottier V, Clement J, Garraway N, McAlister V, Tien HC: Causes of death in Canadian Forces members deployed to Afghanistan and implications on tactical combat casualty care provision. Journal of Trauma, Injury, Infection, and Critical Care 2011, 71:S401-S407.

19. Rigg JL, Mooney SR: Concussions and the military: issues specific to service members. PM\&R 2011, 3:S380-S386. 
20. Patzkowski JC, Blair JA, Schoenfeld AJ, Lehman RA, Hsu JR, Consortium STR: Multiple associated injuries are common with spine fractures during war. Spine J 2011, Epub ahead of print.

21. Macharia WM, Njeru EK, Muli-Musiime F, Nantulya V: Severe road traffic injuries in Kenya: quality of care and access. Afr Health Sci 2009, 9:118-124.

22. Roy N, Murlidhar V, Chowdhury R, Patil SB, Supe PA, Vaishnav PD, Vatkar A: Where there are no emergency medical services - prehospital care for the injured in Mumbai, India. Prehospital Disaster Medicine 2010, 25:145-151.

23. Jayaraman S, Mabweijano JR, Lipnick MS, Caldwell N, Miyamoto J, Wangoda R, Mijumbi C, Hsia R, Dicker R, Ozgediz D: First things first: effectiveness and scalability of a basic prehospital trauma care program for lay first-responders in Kampala, Uganda. PLoS Medicine 2009, 11:e6955.

24. Jayaraman S, Mabweijano J, Lipnick MS, Caldwell N, Miyamoto J, Wangoda R, Mijumbi C, Hsia R, Dicker R, Ozgediz D: Current patterns of prehospital trauma care in Kampala, Uganda and the feasibility of a lay-first-responder training program. World Journal of Surgery 2009, 33:2512-2521

25. Tiska MA, Adu-Ampofo M, Boakye G, Tuuli L, Mock CN: A model of prehospital trauma training for lay persons devised in Africa. Emergency Medicine Journal 2004, 21:237-239.

26. Geduld H, Wallis L: Taxi driver training in Madagascar: the first step in developing a functioning prehospital emergency care system. Emergency Medicine Journal 2011, 28:794-796.

27. Husum H, Gilbert M, Wisborg T, Van Heng Y, Murad M: Rural prehospital trauma systems improve trauma outcome in low-income countries: a prospective study from North Iraq and Cambodia. Journal of Trauma, Injury, Infection, and Critical Care 2003, 54:1188-1196.

28. Wisborg T, Murad MK, Edvardsen O, Husum H: Prehospital trauma system in a low-income country: system maturation and adaptation during 8 years. Journal of Trauma, Injury, Infection, and Critical Care 2008, 64:1342-1348.

29. Roudsari BS, Nathens AB, Cameron P, Civil I, Gruen RL, Koepsell TD, Lecky FE, Lefering RL, Liberman M, Mock CN, et al: International comparison of prehospital trauma care systems. Injury 2007, 38:993-1000.

30. Arreola-Risa C, Vargas J, Contreras I, Mock C: Effect of emergency medical technician certification for all prehospital personnel in a Latin American city. Journal of Trauma, Injury, Infection, and Critical Care 2007, 63:914-919.

31. Mock C: Strengthening care for the injured globally. Journal of Trauma, Injury, Infection, and Critical Care 2011, 70:1307-1316.

32. Mock C, Lormand JD, Goosen J, et al: Guidelines for Essential Trauma Care. Geneva: World Health Organization; 2004.

33. Mock C, Joshipura M, Goosen J, Maier R: Overview of the essential trauma care project. World Journal of Surgery 2006, 30:919-929.

34. Mock C, Joshipura M, Goosen J, et al: Strengthening trauma systems globally: The essential trauma care project. Journal of Trauma, Injury, Infection, and Critical Care 2005, 59:1243-1246.

35. Vo D, Cherian MN, Bianchi S, McCunn M: Anesthesia capacity in 22 low and middle income countries. San Diego, CA: Alliance for Surgery and Anesthesia Presence (formerly Global Burden of Surgical Disease) meeting; 2011.

36. Abdullah F, Troedsson H, Cherian M: The World Health Organization program for emergency surgical, obstetric, and anesthetic care: from Mongolia to the future. Arch Surg 2011, 146:620-623.

37. Chadbunchachai W, Sriwiwat S, Kulleab S, Saranrittichai S, Chumsri J, Jaikwang $P$ : The comparative study for quality of trauma treatment before and after the revision of trauma audit filter, Khon Kaen Hospital 1998. Journal of the Medical Association of Thailand 2001, 84:782-790.

38. Taira BR, Cherian MN, Yakandawala H, Kesavan R, Samarage SM, DeSilva M: Survey of emergency and surgical capacity in the conflict-affected regions of Sri Lanka. World Journal of Surgery 2010, 34:428-432.

39. Crisp N, Gawanas B, Sharp I: Training the health workforce: scaling up, saving lives. Lancet 2008, 371:689-691.

40. Walker IA, Wilson $\mathrm{IH}$ : Anaesthesia in developing countries - a risk for patients. Lancet 2008, 371:968-969.

41. Cherian MN, Choo S, Wilson I, et al: Building and retaining the neglected anaesthesia health workforce: is it crucial for health systems strengthening through primary health care? Bulletin of the World Health Organization 2010, 88:637-639.
42. Hodges SC, Mijumbi C, Okello M, et al: Anaesthesia services in developing countries: defining the problems. Anaesthesia 2007, 62:4-11.

43. Dubowitz G, Detlefs S, McQueen KA: Global anesthesia workforce crisis: a preliminary survey revealing shortages contributing to undesirable outcomes and unsafe practices. World Journal of Surgery 2010, 34:438-444.

44. Bianchi S, Cherian MN, Vo D, McCunn M: Lack of trained anesthesia workforce in low and middle income countries. San Diego, CA: Alliance for Anesthesia and Surgery Presence; 2011.

45. McQueen KAK, Hyder JA, Taira BR, Semer N, Burkle FM, Casey KM: The provision of surgical care by international organizations in developing countries: a preliminary report. World Journal of Surgery 2010, 34:397-402.

46. Vermund SH, Sahasrabuddhe W, Khedkar S, Jia Y, Etherington C, Vergara A: Building global health through a center-without-walls: the Vanderbilt Institute for Global Health. Academic Medicine 2008, 83:154-164.

47. Stapleton FB, Wahl PW, Norris TE, Ramsey PG: Addressing global health through the marriage of public health and medicine: developing the University of Washington Department of Global Health. Academic Medicine 2006, 81:897-901.

48. Quinn TC: The Johns Hopkins Center for Global Health: transcending borders for world health. Academic Medicine 2008, 83:134-142.

49. Lorntz B, Boissevain JR, Dillingham R, Kelly J, Ballard A, Scheld WM, Guerrant RL: A trans-university center for global health. Academic Medicine 2008, 83:165-172.

50. Fulton BD, Scheffler RM, Sparkes SP, Auh EY, Vujicic M, Soucat A: Health workforce skill mix and task shifting in low income countries: a review of recent evidence. Hum Resour Heal 2011, 11:1.

51. Van Heng Y, Davoung C, Husum H: Non-doctors as trauma surgeons? A controlled study of trauma training for non-graduate surgeons in rural Cambodia. Prehospital Disaster Medicine 2008, 23:483-489.

52. Lavy C, Sauven K, Mkandawire N, Cherian MN, Gosselin R, Ndihokubwayo JB, Parry E: State of surgery in tropical Africa: a review. World Journal of Surgery 2011, 35:262-271.

53. Ali J, Adams R, Butler AK, et al: Trauma outcome improves following the advanced trauma life support program in a developing country. Journal of Trauma, Injury, Infection, and Critical Care 1993, 34:890-898.

54. Ali J, Adams R, Stedman M, Howard M, Williams Jl: Advanced trauma life support program increases emergency room application of trauma resuscitative procedures. Journal of Trauma, Injury, Infection, and Critical Care 1994, 36:391-394

55. Bergman S, Deckelbaum D, Lett R, Haas B, Demyttenaere S, Munthali V, Mbembati N, Museru L, Razek T: Assessing the impact of the trauma team training program in Tanzania. Journal of Trauma, Injury, Infection, and Critical Care 2008, 65:879-883.

56. Sakran JV, Kaafarani HM, Prabhakaran S, Nitzschke S, Casey K: Enhancing American Surgical Training: meeting the challenges of a globalizing world. American College of Surgeons Bulletin 2012, 97:20-26.

57. McLaughlin T, Hennecke P, Garraway NR, Evans DC, Hameed M, Simons RK, Doucet J, Hansen D, Annand S, Bell N, et al: A predeployment trauma team training course creates confidence in teamwork and clinical skills: a post-Afghanistan deployment validation study of Canadian Forces healthcare personnel. Journal of Trauma, Injury, Infection, and Critical Care 2011, 71:S487-S493.

58. Margolis CZ, Deckelbaum RJ, Henkin Y, Baram S, Cooper P, Alkan ML: A medical school for international health run by international partners. Academic Medicine 2004, 79:744-751.

doi:10.1186/1757-7241-20-64

Cite this article as: Sakran et al.: Care of the injured worldwide: trauma still the neglected disease of modern society. Scandinavian Journal of Trauma, Resuscitation and Emergency Medicine 2012 20:64. 